\title{
国家助学金评选过程中存在的问题及应对措施
}

\section{The Problems and Countermeasures in the Selection of National Grants}

\author{
徐沛 \\ Pei $\mathrm{Xu}$ \\ 武汉学院 中国·湖北 武汉 430210 \\ Wuhan College, Hubei, Wuhan, 430210, China
}

\begin{abstract}
摘 要: 国家助学金评选工作是高校学生工作中的一项重要内容, 其肩负着资助和育人两大功能, 但实际在实施过程中存 在一些困难和问题。本文作者结合自身辅导员工作经历揭示了当下高校国家助学金在评选过程中存在的问题，并提出了一 些建议和应对措施。
\end{abstract}

\begin{abstract}
The selection of national grants is an important part of the college student affairs.It contains two major functions: financial aid and education.But there are some difficulties and problems in the process of implementation.This paper based on the author's experience of counselors,reveals the current problems in the implementation of the national grants, and puts forward some suggestions and countermeasures.
\end{abstract}

关键词: 助学金; 评选; 问题; 应对措施

Keywords: national grants; selection; problems; countermeasures

DOI: $10.36012 /$ sde.v3i1.2868

\section{1 引言}

国家助学金是由中央与地方政府按照一定比例出资设 立的, 目的是资助家庭经济困难的全日制普通本专科在校学 生的学习, 让其能顺利完成学业。为贯彻落实党的十九大精 神和 2019 年《政府工作报告》等有关要求，经国务院同意， 从 2019 年起扩大了助学金的覆盖面, 同时提高了补助标准。 一等助学金从原来每生每年 4000 元提高到 4400 元，二等从 每生每年 3000 元提高到 3300 元，三等从每生每年 2000 元 提高到 2200 元。国家助学金制度充分体现了党和国家对贫 困大学生的人文关怀。国家助学金肩负着资助和育人两大功 能, 资助体现在物质的帮助, 如资助金的发放, 育人功能则 体现在对大学生的激励和导向作用, 重在影响大学生的思想 和行为, 比如培养大学生的诚信教育、感恩教育、爱国教育、 励志教育以及公平教育等 ${ }^{[1]}$ 。但从其实施的总体情况来看, 国家助学金制度的育人功能并未得到有效发挥，结合辅导员 工作实际, 谈一下在助学金评选实施过程中的一些问题和应
对措施。

\section{2 助学金评选过程中存在的问题}

\section{1 宣传力度不够}

每年国家助学金的评选在 9 到 11 月份集中进行，但是 高校在实际操作的过程中往往只重视评选的过程和结果, 对 于奖助学金的宣传力度较小。同学们很多不了解国家关于助 学金的政策、评选标准、评选流程以及助学金使用用途。部 分学生认为只要被认定贫困了，就一定会被评上助学金，因 此想尽各种办法申请贫困认定，增加了贫困认定的难度。而 一些真正贫困的同学又不了解认定标准和评选流程, 觉得准 备资料麻烦、错过机会。也有一些真正的贫困的，比如建档 立卡或者低保的同学压根不知道自己家里的情况, 自己家里 是低保或者建档立卡都不清楚, 而错过申请机会。

\section{2 评选标准和流程不完善}

根据《财政部、教育部关于印发《普通本科高校、高 等职业学校国家助学金管理暂行办法》的通知财教 [2007]

【作者简介】徐沛（1991 ), 女, 汉, 湖北黄冈人, 硕士, 助教, 从事思想政治教育研究。 
92 号, 各大高校在此基础上制定的国家助学金评选办法, 其规定性选条件过于模糊，文件中规定助学金的基本申请条 件为 : 热爱社会主义祖国, 拥护中国共产党的领导; 遵守宪 法和法律, 遵守学校规章制度; 诚实守信, 道德品质优良; 勤奋学习, 积极上进; 家庭经济困难, 生活佮朴。总体来看, 条件过于笼统, 因此现实中很难具体去操作, 不能做到精准。 因此也不乏家庭不贫困的学生, 利用模糊的评判标准来钻空 子, 导致一些家庭贫困的同学被占掉名额, 错过机会。再加 上由于我国各地区经济发展的差异性, 各地区对贫困生的衡 量标准也不完全一致, 这也使得评选工作增加了难度。 ${ }^{[2]}$ 在 评选流程方面, 大部分高校助学金评选工作都是依靠辅导员 来具体实施, 但每个高校辅导员带班情况不一样, 有的高校 辅导员带班较多, 精力无法分散, 因此助学金的评定工作很 大程度上直接交给了班委, 班委在操作中流程过于简单, 很 大程度上依靠投票来进行, 而有些贫困生较为内向, 平时与 同学沟通接触不多的, 因为不了解, 导致投票中落选或者等 级靠后。

\section{3 贫困认定难度大}

一般申请贫困认定首先需要提交《高校学生家庭情况 调查表》, 2019 年以前调查表上除了填写家庭经济情况的一 些基本信息, 还需要学生所在乡镇及街道民政部门的盖章。 2019 年教育部将大学生申请相关困难资助时, 由原来需要 家乡所在地乡镇或街道民政部门对学生家庭经济情况进行 证明的环节直接改为申请人书面承诺, 此举大大减轻了学生 和家长的负担, 不用来回奔波去开证明和找人盖章就可以完 成高校助学金等申请, 不仅方便学生办事, 也提高工作效率。 并且家庭经济情况证明并不都是真实的, 有些学生家庭条件 较好但是也能利用关系在当地开到相关证明, 有些真实贫困 的却因为开不到证明就放弃申请。但是, 直接改为个人承诺, 也存在一定的不足, 这个需要申请人绝对的诚信, 同时针对 学生所提交的个人承诺的家庭经济调查表及相关材料, 辅导 员又无法去实地考证, 这其中不乏一些同学受到利益驱使, 填写假材料, 无疑增加了认定的难度。

\section{4 重资助轻育人}

现实中, 不少高校助学金还停留在 “资助” 阶段, “育人” 功能没有彰显。大部分高校助学金评选这一块并没有设置专 门的管理人员, 都是由辅导员或者班主任来兼任, 由于辅导
员事务性工作较多, 所带班级以及学生人数过多, 往往更关 心的是如何完成助学金的评选工作以及资助金额的下发工 作, 只要过程中没有学生投诉, 基本工作就到此结束了。而 对于如何发挥奖助学金的育人作用, 没有很好的去探索。对 于贫困生后期的关注与跟踪, 也几乎没有。以至于助学金也 只是解决了学生的一小部分生活上的困难, 对于这一类学生 的能力提升、感恩教育、诚信教育、励志教育基本缺失。高 校不应只停留在资助贫困生的生活方面, 更应该注重培养他 们自身的技能，来达到自强脱贫的效果。

\section{3 完善助学金评选工作的应对措施}

\section{1 对国家助学金制度进行充分地宣传}

高校应该加强对助学金制度和政策的宣传, 让学生懂 得国家设立助学金的根本宗旨、理解助学金制度存在的意义 及其价值。在国家助学金评选工作开启之前, 可以通过主题 班会、讲座、新媒体等形式对国家助学金制度进行宣传。宣 传的内容包括 : 国家及政府设立助学金的目的和意义、助学 金的资金来源及构成、申请和获得的条件、评选程序、使用 途径以及获得国家奖助学金后应该履行的义务等 ${ }^{[2]}$ 。要让每 个同学对国家助学金有一个较为全面的认识, 助学金是党和 国家对家庭经济困难的学生的关怀,帮助其顺利完成学业。[3] 只有这样才有可能让学生树立正确的申请动机, 而不是受利 益驱使将助学金当作一项免费的福利, 占用贫困生的名额。

\section{2 规范和完善助学金评选标准和程序}

在评选标准方面, 贫困是很难去量化的, 很多学生在 填表时写的家庭情况较为笼统, 比如务农或者自由工作者或 者家庭主妇，但实际情况是有收入的，并且重大疾病或突发 状况, 什么样的疾病是重大疾病, 这个也很难去界定。因此, 我们应当考虑多维度的评判指标, 比如将学生的家庭经济收 人情况、学生的日常消费情况、勤工助学情况、奖助贷情况、 任课老师和同班同学的评价等作为量化评估的主要参考因 素, 也可以利用学生一卡通等大数据平台实行实时监测, 通 过对学生的饮食消费、购物消费、通讯消费等数据的分析来 了解学生的实际消费水平。尽可能的将定量观测和定性评价 合理结合起来。 ${ }^{[4]}$

在评选流程方面，应该结合“本人申请、资格审查、班 级民主评议、院系评审、公示、学校审核”的贫困生认定程 
序, 坚持公开、公平、公正的原则, 做好学生申请、民主评议、 院系初审公示、学校复审等各环节工作。其中班级评议小组 由辅导员担任组长, 学生干部、党员、普通学生代表作为小 组成员 ${ }^{[5]}$, 充分核实学生所提交的材料, 并针对性地通过走 访宿舍、同学谈话等多方面了解情况, 并将评选结果在班级 以及院系公示, 一定不可以直接甩手给班委, 以简单的投票 的形式或者直接按考试成绩确定评选结果和等级。

\section{3 将资助与育人相结合}

资助不只是物质的帮助, 应该在获得经济资助的基础 上, 培养受资助学生的诚信教育、感恩教育以及励志教育。 在助学金评选之前可以通过开展诚信主题班会、签订诚信承 诺书等方式传达诚信理念, 树立诚信之风。其次, 要做好助 学金政策的相关说明, 让学生知道这是党和国家对于贫困生 的关怀, 我们接受了国家社会的帮扶, 要以感恩的心态来回 馈国家和社会。并且助学金获得者中也不乏自强不息的励志 品质, 因此在国家助学金评定工作完成后, 应当充分挖掘先 进人物事迹, 利用网络等宣传阵地, 大力宣传国家助学金获 得者的先进事迹, 彰显先进模范的示范和导向作用。

\section{4 将资助与能力发展相结合}

授人以鱼不如授人以渔, 资助不应只是简单的物质的 帮助，而应是多维度的的，除了在经济上给予贫困生帮扶， 也应该注重其能力的培养, 要将引导学生全面发展作为资助 工作的长远目标。因此, 我们在实际操作过程中, 要为家庭 经济困难学生建立相关台账, 充分了解每个学生的家庭情 况、学业情况、性格特征、思想动态等, 在此基础上为这些 学生提供从物质、思想和能力等三个维度的全方位的个性化
资助 ${ }^{[2]}$ 。例如可以针对这些学生的特征提供一些既能通过劳 动获得报酬改善个人经济状况的, 又能锻炼其自身能力的勤 工助学岗位, 再者帮扶也因关注学生当前亟待解决的问题, 例如对于毕业班贫困生，告诉他们简历制作、面试等技巧， 推荐相关岗位, 帮助其获得就业机会、加强个人能力等。帮 扶不应只是暂时的, 要长期关注, 并根据学生不断发展的状 况随时作出调整。

\section{4 结语}

助学金肩负着资助和育人两大功能，助学金的实施既 是促进教育公平的重要举措, 也是大学生思想政治教育的重 要阵地。因此作为高校教育工作者, 我们不能简单地把国家 助学金制度的实施看作是物质和金钱上的帮扶工作，而应从 做好大学生思想政治教育、促进大学生成长成才的高度, 充 分挖掘和发挥国家助学金的育人功能, 只有如此, 才能真正 发挥国家助学金制度实施的效果。

\section{参考文献}

[1] 王丽娟. 民办高校学生资助工作育人功能发挥研究一以 $\mathrm{A}$ 民 办高校为例 $[\mathrm{D}]$ 《西安理工大学硕士论文》, 2015

[2] 翁文香. 国家奖助学金育人功能的实践反思与提升路径优化 [J]. 锦州医科大学报, 2019(2): 5-8

[3] 王封青. 精准资助视域中高校资助育人工作机制探究 [J]. 现代 交际期刊 -2020(3): 36-37

[4] 谭亚男. 高校资助育人精准化研究 [D]. 广西师范学院, 2017(6)

[5] 潘堂忠. 家庭经济困难学生认定工作的实施研究 [J]. 科技资讯, 2012(5): 211-212

\section{(上接第 93 页)}

在这种情况的原因有很多，但是职业院校的课堂出现了问 题, 这是无可置疑的。作为教育工作者, 无论是职业院校还 是本科院校的教师, 都应该不忘初心, 牢记使命, 不断开拓 进取, 为祖国和社会培养高素质人才。

\section{参考文献}

[1] 吴杰莹. 职业院校德育课有效教学的实践探索 [J]. 职业教育研 究, 2018(6): 49-51.
[2] 谢晓华, 刘晓青. 机电设备维修与管理专业课堂教学诊断与改 进框架的建立 [J] 科教导刊 (下旬 ), 2018. (6): 138-139.

[3] 李明强, 孙东辉. 教学诊改视角下的课堂教学诊量要素研究 [J]. 时代教育, 2018(11): 202-203.

[4] 刘海玲. 简约数学课堂教学中预案的执行 [J]. 教育科研论坛, 2019(1): 87-88. 